\section{New concept: treating nonproliferative diabetic retinopathy with light adaptation of rods during sleep}

Eye (2011) 25, 1533-1534; doi:10.1038/eye.2011.263; published online 4 November 2011

Arden $e t a l^{1,2}$ have tested the hypothesis that keeping an eye with mild diabetic retinopathy light adapted during sleep will substantially reduce rod oxygen consumption, and thus will have remedial effects on the disease by making the retina less hypoxic. In the dark, rods maintain the phototransduction dark current, and the result is oxygen consumption by rods in the dark is greater than any other cell in the retina. ${ }^{3}$ In experiments by Okawa et $\mathrm{al}^{4}{ }^{4}$ bright light decreased retinal $\mathrm{O}_{2}$ consumption in the mouse by $40-60 \%$; they found that the decrease is mostly due to a drop in ATP consumption by the rods. Photoreceptors reside in an avascular zone and thus obtain oxygen by diffusion, mainly from the choroid, and also from the inner retinal circulation in dark. Studies in cat and macaque retinae in which oxygen microelectrodes are advanced from inner retina to choroid found a $30-40 \% \mathrm{PO}_{2}$ difference between inner retina and the vicinity of rods. ${ }^{5-7}$ There was no detectable oxygen levels next to dark-adapted rods. In fact measurements in the outer plexiform layer found a large oxygen tension drop to zero, suggesting that there is a flow of oxygen from the inner retinal circulation to rods in the dark. ${ }^{1}$

Studies have appeared regularly in the ophthalmological literature during the last 30 years showing that oxygen levels are lowest in the region of dark-adapted rods, and reducing hypoxia in diabetics by breathing oxygen improved retinal function, for example, colour vision, ERG oscillatory potentials, or dark-adaptation sensitivity, but had no effect in normal subjects.
JR Heckenlively

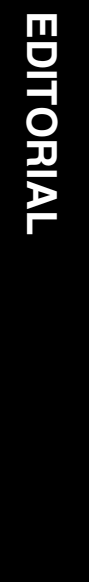

The project by Arden ${ }^{1,8}$ reported in this issue $^{9}$ tested the hypothesis that light adaptation of rods in sleeping patients with diabetic retinal oedema would improve with the use of light masks during sleep. This work was developed in clinical experiments by Professor Arden $e t a l^{1}$ over more than a decade with step-by-step research: Documentation of how much light transmits through eyelids, what wavelength of light generated by light-emitting diodes (LEDs) would be optimal in lightadapting rods, but at intensities just enough to decrease oxygen consumption, but not enough to disturb the patients' sleep. Disposable light masks were designed with LEDs run by batteries, and thus were safe to the patient and easy to replace.

Even as a pilot study, the results in their paper are striking, and proof of principle appears to be validated. This report also raises questions whether research studies should be explored to see if light-adaptation therapy might be useful for treating or preventing wet AMD in high-risk patients? It is notable that most of the CNV seen in AMD patients occurs in the rod-rich region of the parafovea, and the hypoxia created by dark-adapted rods could well contribute to stimulating VEGF and CNV formation in AMD.

Diabetic retinopathy is one of the common afflictions in poorer countries, and an inexpensive and effective method of slowing or treating nonproliferative diabetic retinopathy could have great benefits. Patients unable to afford more expensive injections or laser treatment might still benefit from properly delivered light therapy at a fraction of the cost. However, the limits and expected benefits of
University of Michigan, Kellogg Eye Center, Ann Arbor, MI, USA

Correspondence: JR Heckenlively, University of Michigan, Kellog Eye Center, 1000 Wall Street, Ann Arbor, MI 48105, USA Tel: +17347632280 Fax: + 17346470088 E-mail: jrheck@umich.edu 
light-adaptation therapy in diabetes will need additional research and clinical trials to clarify its indications and usefulness.

\section{Conflict of interest}

The author declares no conflict of interest.

\section{References}

1 Arden GB, Wolf JE, Collier J, Wolff C, Rosenberg M. Dark Adaptation is impaired in diabetics before photopic visual losses can be seen. Can hypoxia of rods contribute to diabetic retinopathy? In: Hollyfield JG (ed.). Retinal Degenerative Diseases and Experimental Therapy. Plenum Press: NY, 1999; 305-325.

2 Dean F, Dornhorst A, Arden GB. Partial reversal of protan and tritan colour defects wit inhaled oxygen in insulin dependent diabetic subjects. Brit J Ophthalmol 1997; 81: 27-30.
3 Wang S, Birol G, Budzynski E, Flynn R, Linsenmeier RA. Metabolic responses to light in monkey photoreceptors. Curr Eye Res 2010; 35: 510-518.

4 Okawa H, Sampath AP, Laughlin SB, Fain GL. ATP consumption by mammalian rod photoreceptors in darkness and in light. Curr Biol 2008; 18: 1917-1921.

5 Linsenmeier RA, Braun RD. Oxygen distribution and consumption in the cat retina during normotension and hypoxaemia. J Gen Physiol 1992; 99: 177-197.

6 Ahmed J, Braun RD, Dunn R, Linsenmeier RA. Oxygen distributionin the macaque retina. Invet Ophthalmol Vis Sci 1993; 34: 516-521.

7 Linsenmeier RA. The effects of light and darkness on oxygen distribution and consumption in the cat retina. J Gen Physiol 1986; 88: 521-542.

8 Arden GB, Wolf JE, Tsang Y. Does dark adaptation exacerbate diabetic retinopathy? Evidence and a linking hypothesis. Vision Res 1998; 38: 1723-1729.

9 Arden GB, Jyothi S, Hogg CH, Lee YF, Sivaprasad S. Regression of early diabetic macular oedema is associated with prevention of dark adaptation. Eye 2011; 25(12): 1546-1554. 